\title{
ACESSIBILIDADE DE PESSOAS DEFICIENTES VISUAIS À PRÁTICA DA NATAÇÃO - UMA REVISÃO DA LITERATURA
}

Bruna Bredariol, Universidade Estadual de Campinas - UNICAMP, Campinas - Brasil José Júlio Gavião de Almeida, Universidade Estadual de Campinas - UNICAMP, Campinas - Brasil

\section{RESUMO}

Este trabalho teve como finalidade discutir a acessibilidade das pessoas deficientes visuais à prática da natação nas instituições privadas de ensino da modalidade, levando em consideração tanto as barreiras arquitetônicas, como as barreiras sociais e humanas ainda existentes na sociedade brasileira. Para isto, foi realizada uma revisão de literatura composta pelos trabalhos mais relevantes que trataram dos assuntos em questão nos últimos anos. Com a realização deste estudo foi possível perceber que a acessibilidade para a prática da natação pelas pessoas deficientes visuais ainda é muito precária no país, considerando que estes fazem parte da sociedade e deveriam ter as mesmas condições de acesso que toda a população.

Palavras-Chave: Pessoas deficientes visuais; Natação; Acessibilidade.

\section{ACCESSIBILITY FOR VISUALLY IMPAIRED PEOPLE IN SWIMMING PRACTICE - A LITERATURE REVIEW}

\begin{abstract}
This study aimed to discuss the accessibility of visually impaired people in swimming practice in private institutions of the sport, taking into account both the architectural barriers, such as human and social barriers that still exist in Brazilian society. For this, we performed a literature review comprises the most relevant papers which dealt with matters in question in recent years. With this study it was revealed that accessibility to the sport of swimming by visually impaired people is still very poor in the country, considering that these are part of society and should have the same access to the entire population.
\end{abstract}

Key-Words: Visual Impaired People; Swimming; Accessibility. 


\section{ACCESIBILIDAD PARA PERSONAS CON DISCAPACIDAD VISUAL EN PRÁCTICA DE LA NATACIÓN - UNA REVISIÓN DE LA LITERATURA}

\section{RESUMEN}

Este estudio tuvo como objetivo analizar la accesibilidad de personas con discapacidad visual en la práctica de natación en las instituciones privadas de este deporte, teniendo en cuenta tanto las barreras arquitectónicas, como las barreras humanas y sociales que aún existen en la sociedad brasileña. Para ello, se realizó una revisión de la literatura comprende los artículos más relevantes que se tratan los asuntos en cuestión en los últimos años. Con este estudio se reveló que la accesibilidad al deporte de la natación por las personas con discapacidad visual es todavía muy pobre en el país, teniendo en cuenta que estos son parte de la sociedad y deben tener el mismo acceso a toda la población.

Palabras-Clave: Personas con discapacidad visual; Natación; Accesibilidad. 


\section{INTRODUÇÃO}

A questão da inclusão de pessoas deficientes dentro da sociedade brasileira já vem sendo discutida há algum tempo por estudiosos de diversas áreas de conhecimento, inclusive na área da Educação Física e Esportes. Segundo a Organização Mundial da Saúde (OMS), ${ }^{1}$ a deficiência pode ser definida como sendo "uma anomalia da estrutura ou da aparência do corpo humano e do funcionamento de um órgão ou sistema, seja qual for sua causa".

Mais especificamente a deficiência visual, a qual atinge, aproximadamente, 6,9\% da população brasileira, ${ }^{2}$ pode ser definida, segundo o Ministério da Saúde, ${ }^{3}$ como "uma situação irreversível de diminuição da visão, mesmo após tratamento clínico e/ou cirúrgico e uso de óculos convencionais".

Pessoas que possuem a deficiência visual desde criança podem possuir um atraso em seu desenvolvimento motor. Isto, quando ocorre, acontece devido ao fato de que as experiências motoras dessa criança são limitadas, muitas vezes, por falta de estímulos, tal como o de um ambiente restrito. ${ }^{4}$ Nesse contexto de ausência de oportunidades para o desenvolvimento motor, vê-se nos estudos de Nabeiro in Mazarini ${ }^{5: 17}$ que:

O indivíduo deficiente visual apresenta: defasagem no desenvolvimento motor; locomoção insegura; pouco controle e consciência corporal; defeitos de postura; expressão pobre; inatividade e insegurança. Além disso, grande parte dos deficientes visuais apresenta quadros de sedentarismo, obesidade, dificuldade de relaxamento, tônus muscular elevado, pouca flexibilidade, inibição motora, baixa resistência física etc.

Sendo assim, muitos autores consideram a importância da prática de atividades físicas no desenvolvimento motor, cognitivo e social dos deficientes visuais, proporcionando a estes uma melhor condição e qualidade de vida, além de ser uma forma para concretizar a inclusão destes dentro da sociedade. A natação, se bem direcionada e explorada, pode ser considerada como uma atividade que oferece muitos benefícios, quer pelos seus efeitos terapêuticos, quer pelos benefícios utilitários ou pela ludicidade que o meio aquático proporciona. ${ }^{4}$ Segundo Adams, ${ }^{6: 355 ~ " u m a ~ d a s ~ m a i o r e s ~ v a n t a g e n s ~ d o ~ t r a t a m e n t o ~ e m ~ p i s c i n a ~}$ são os efeitos positivos decorrentes da imersão do corpo em água morna". O autor ainda coloca que o calor da água favorece também o relaxamento dos músculos e anima o indivíduo a continuar explorando a movimentação dentro da água. ${ }^{6}$ Dessa forma, o 
indivíduo se sente mais seguro em realizar movimentos novos, contribuindo para seu desenvolvimento motor e cognitivo. ${ }^{6}$

Apesar de muitos estudos apresentarem os benefícios da natação para o desenvolvimento global das pessoas deficientes visuais, a prática da modalidade por esta população específica ainda parece muito restrita e precária no Brasil. Neste contexto há necessidade de trabalhos que comprovem a precariedade existente na prática de natação pelas pessoas deficientes visuais no país, além de viabilizar a maior participação de instituições de ensino da natação no processo de inclusão das pessoas deficientes visuais no esporte, incentivando-as a aceitá-los e proporcionando-lhes os meios para isto, pois, acredita-se ser a falta de preparação destas instituições para receber as pessoas deficientes, que acarreta, em grande parte, a falta de participação destes no esporte. Tendo como base estes fatores, o objetivo deste trabalho é analisar os principais problemas enfrentados pela pessoa deficiente visual em relação à prática da natação, sua aceitação nas instituições e as possibilidades para que estes problemas sejam amenizados.

\section{METODOLOGIA}

$\mathrm{O}$ artigo trata-se de uma revisão bibliográfica, ${ }^{7}$ na qual foram pesquisados os principais trabalhos sobre os aspectos teóricos que permeiam o tema da acessibilidade das pessoas deficientes visuais na prática da natação dos últimos anos. Dessa forma, foram pesquisadas referências sobre as pessoas deficientes e a sociedade, sobre o processo de inclusão destas pessoas no esporte, sobre o esporte específico para as pessoas deficientes visuais e, por fim, sobre a natação para esta população.

Para que fosse realizada, a pesquisa foi baseada em publicações (livros, monografias, teses e dissertações) encontradas na biblioteca da Faculdade de Educação Física (FEF) da Universidade Estadual de Campinas (UNICAMP). Além disso, a pesquisa também teve como fontes as publicações encontradas nas bases de dados eletrônicas, como o Sistema de Bibliotecas da Unicamp (SBU), e revistas eletrônicas referentes à área da Educação Física e Esportes (Movimento, Revista Digital e Revista Brasileira de Ciência do Esporte). 


\section{A PESSOA DEFICIENTE E A SOCIEDADE}

A relação da sociedade com as pessoas deficientes vem se modificando no decorrer da história, tanto no que se refere aos pressupostos filosóficos que a determinam e permeiam como no conjunto de práticas nas quais ela se objetiva. ${ }^{8}$

De acordo com Carmo, ${ }^{9}$ os problemas sociais enfrentados pelas pessoas deficientes acompanham o homem desde os tempos mais antigos da civilização. $\mathrm{O}$ autor relata que, nas culturas mais primitivas, as quais sobreviviam basicamente da caça e da pesca, estas pessoas, geralmente, eram abandonadas em ambientes agrestes e perigosos, sendo que a morte se dava por inanição ou por ataques de animais ferozes. ${ }^{9}$

Durante muito tempo na história, a existência de algum tipo de deficiência foi considerada como obra de maus espíritos, sendo sinal de impureza e pecado. ${ }^{9}$ Além disso, o autor ainda coloca que as amputações como forma de punição e estigmatização eram práticas comuns entre os povos mais antigos, como os egípcios. Estes sinais tinham por objetivo informar a todos quem era escravo, criminoso ou traidor. ${ }^{9}$

Somente a partir do século XVII que a relação da sociedade com as pessoas com deficiência passou a se diversificar, caracterizando-se por iniciativas de Institucionalização Total, de tratamento médico e de busca de estratégias de ensino. ${ }^{8}$ As Instituições Totais eram caracterizadas pela retirada das pessoas com deficiência de suas comunidades de origem e pela manutenção destas em instituições residenciais segregadas ou escolas especiais. Dessa forma as pessoas deficientes eram mantidas isoladas da sociedade, fosse para proteção, tratamento ou processo educacional. ${ }^{8}$

A partir da década de 60, iniciou-se no mundo ocidental um movimento baseado na ideologia da normalização, como uma tentativa de integrar a pessoa deficiente na sociedade. ${ }^{8}$ Essa ideologia tinha por base a idéia de que estas pessoas deveriam ser retiradas das instituições e serem colocadas num sistema o mais próximo possível do estilo de vida considerado normal pela sociedade. ${ }^{8}$ 
Mas, apesar das iniciativas de tentar integrar a pessoa com deficiência na sociedade, este processo ainda estava focado no sujeito em questão, o que gerou muitas críticas na época. Estas críticas se baseavam no fato de que, cabe também à sociedade se reorganizar de forma a garantir o acesso de todos os cidadãos, inclusive das pessoas com algum tipo de deficiência, a tudo o que a constitui e caracteriza, independente de quão próximos estejam do nível de normalidade. ${ }^{8}$

Dessa forma, se buscou a disponibilização de instrumentos que viabilizassem a garantia de que a pessoa deficiente pudesse acessar todo e qualquer recurso da comunidade, sendo estes físicos, materiais, humanos, sociais, legais etc. Neste contexto entra em vigor um novo conceito sobre a relação da sociedade com as pessoas deficientes: a inclusão social. Esta se caracteriza não mais só pela modificação do sujeito para se inserir na sociedade, mas por um processo de ajuste mútuo, onde a sociedade também deve promover esta acessibilidade. $^{8}$

De acordo com Cordeiro, ${ }^{10}$ a principal diferença que existe entre os dois conceitos é que, no modelo organizacional que se constrói sob a influência do princípio da integração, as pessoas com deficiência se adaptam às exigências institucionais. Já no modelo da inclusão, a instituição é que deve se adaptar às necessidades das pessoas com deficiência e viceversa. $^{10}$

Para Sassaki, ${ }^{11: 3}$ a inclusão é "o processo pelo qual a sociedade se adapta pra incluir, em seus sistemas sociais gerais, pessoas com necessidades especiais e, simultaneamente, estas se preparam para assumir seus papéis na sociedade". Neste sentido, a inclusão social significa possibilitar às pessoas com deficiência, respeitando as necessidades próprias da sua condição, o acesso aos serviços públicos, aos bens culturais e aos produtos decorrentes do avanço social, político, econômico e tecnológico da sociedade. ${ }^{3}$

O processo de inclusão das pessoas deficientes passou a integrar as normas constitucionais no Brasil com a Constituição Federal de $1988 .{ }^{12}$ De acordo com Santos, ${ }^{12}$ esta constituição criou dispositivos legais em áreas como educação, trabalho, assistência social e acessibilidade física, de forma a garantir a inclusão social das pessoas com deficiência. 
Mas, mesmo com seus direitos assegurados por lei, Santos ${ }^{12}$ diz que a deficiência ainda é compreendida como um fenômeno apenas patológico e não como uma expressão da diversidade humana, o que pode dificultar, por exemplo, que a sociedade assuma a responsabilidade em tratar a deficiência com equidade, ajustando os ambientes sociais às diversidades corporais ou não promovendo políticas de trabalho, educação e assistência social e, assim, reconhecendo as diferenças dessa minoria.

No Brasil, em qualquer área de atenção pública (educação, saúde, esporte, turismo, lazer e cultura) os programas, projetos e atividades são desenvolvidos para as pessoas não deficientes. $^{8}$

Mas não se pode restringir a questão da inclusão das pessoas com deficiência apenas aos fatores de acessibilidade física e aos programas sociais do governo. Como diz Aranha ${ }^{8}$, a democratização da sociedade brasileira passa pela construção de efetivo respeito a essa parcela da população, tanto por parte do governo como por parte da própria população não deficiente que convive com estes dentro da sociedade, englobando também o fator da acessibilidade moral das pessoas deficientes.

\section{O esporte como forma de inclusão}

De acordo com Costa e Sousa, ${ }^{13}$ a educação física somente começa a se preocupar com a atividade física para as pessoas deficientes, aproximadamente, no final dos anos de 1950, sendo que seu enfoque era exclusivamente médico. Os autores ainda completam que os programas de atividades físicas para as pessoas com deficiência eram denominados ginástica médica e tinham por finalidade prevenir doenças, utilizando para tanto exercícios corretivos e de prevenção. ${ }^{13}$

Segundo Araújo, ${ }^{14}$ a visão do esporte como uma forma de inclusão da pessoa deficiente na sociedade surge no início dos anos de 1970, a partir de um movimento, na área de educação física, denominado "Esporte para Todos". Este movimento teve como finalidade principal promover a integração social das pessoas com deficiência. ${ }^{14}$

Após este período, a nova Constituição Brasileira de 1988, passa a se preocupar também com a questão da pessoa deficiente na sociedade, sendo que, em seu artigo 217, aborda

Conexões: revista da Faculdade de Educação Física da UNICAMP, Campinas, v. 10, n. 2, p. 196-213, maio/ago. 2012.202 ISSN: 1983-9030 
especificamente o assunto, estabelecendo que é dever do Estado fomentar práticas desportivas formais e não formais, como direito de cada um. ${ }^{15}$

Mas, durante toda sua história dentro do país, o esporte adaptado passou por vários ministérios e secretarias, o que dificultou bastante uma ação consistente no que se refere à prática de atividades físicas pelas pessoas deficientes, havendo apenas ações individualizadas que não tinham continuidade. ${ }^{15}$ De acordo com Costa e Sousa, ${ }^{13}$ na educação física e esporte adaptado não se pode perceber ações ou práticas que levassem as pessoas deficientes a desenvolverem suas atividades entre pessoas não deficientes. "O objetivo é de integrar socialmente, mas o caráter é segregacionista”. 13:37

Os mesmos autores ainda completam que, a educação física apresentava como concepção um modelo de corpo saudável e produtivo no qual a pessoa deficiente não se enquadrava. ${ }^{13}$ Isto fez com que a educação física adaptada caminhasse de forma separada para atender essa clientela. Sendo assim, pode-se dizer que a educação física e o esporte adaptado pouco caminharam em direção ao princípio da inclusão. ${ }^{13}$

Nem menos ou mais importante que outras ações, o esporte se apresenta como um dos requisitos indispensáveis para que as pessoas com deficiência possam atingir a dimensão total da inclusão social. ${ }^{15}$

\section{A NATAÇÃO E A DEFICIÊNCIA VISUAL}

Para Araujo Júnior, ${ }^{16}$ a natação é considerada como uma das atividades físicas mais completas que existe na atualidade e, através dela, se obtém benefícios que auxiliam o praticante a ter uma vida mais saudável, buscando a otimização e o desenvolvimento das capacidades físicas, flexibilidade, força, resistência muscular, e da capacidade cardiorrespiratória, além de outros muitos benefícios.

Dentre a grande diversidade de benefícios que a natação pode trazer ao indivíduo, damos destaque para a estruturação do esquema corporal. Para Damasceno ${ }^{17}$ o esquema corporal é a "experiência do corpo com a maneira com que este se põe no meio ambiente". 17:30 Portanto, o autor diz que para que um indivíduo se adapte ao meio, ele primeiro deve conhecer e dominar o seu próprio corpo. ${ }^{17}$

Conexões: revista da Faculdade de Educação Física da UNICAMP, Campinas, v. 10, n. 2, p. 196-213, maio/ago. $2012 .{ }^{203}$ ISSN: 1983-9030 
Sendo assim, a natação permite ao indivíduo a exploração e manejo do meio, através de atividades motoras, que contribuem para a estruturação do seu esquema corporal. Ela ajuda cada um a ter noção perceptiva do espaço à sua volta, pois exige a execução de movimentos em diferentes posições. ${ }^{17}$

Como já vimos anteriormente, as pessoas com deficiência, seja de qualquer natureza, tendem a ser menos ativas fisicamente que as outras pessoas, mas possuem as mesmas necessidades em termos de prevenção de doenças e melhora da qualidade de vida. Sendo assim, é importante considerar que os benefícios da prática de atividade física não são diferentes quando nos referimos à pessoa deficiente, desde que os esforços não sejam excessivos em relação à condição física da pessoa. ${ }^{18}$

No que se referem à pessoa deficiente visual, as principais defasagens apresentadas são em relação às habilidades motoras, deixando clara a importância da prática esportiva neste caso específico. Para Paula, ${ }^{18}$ pode-se considerar que a atividade física deve ser trabalhada com o intuito de diminuir defasagens, facilitando a formação e/ou aquisição de conceitos e ampliando as possibilidades de experiências motoras das pessoas com deficiência visual.

A natação é considerada por muitos autores como uma das modalidades esportivas mais completas praticadas nos dias atuais e, no que se referem às pessoas deficientes visuais, as vantagens proporcionadas por sua prática não se diferem. Além dos benefícios já citados anteriormente, a natação pode proporcionar melhorias nas características motoras mais defasadas pela deficiência, como equilíbrio, coordenação e formação do esquema corporal, além de ser uma das poucas modalidades esportivas a possibilitar autonomia completa à pessoa deficiente visual, ou seja, não se faz necessário o auxílio de guias (pessoas videntes). ${ }^{19}$

Para Mazarini, ${ }^{20}$ os exercícios no meio líquido oferecem oportunidades de execução dos mais diferentes movimentos, graças à propriedade de flutuabilidade do corpo na água. De acordo com a autora, "a água aquecida proporciona um aumento da circulação sanguínea e da sensibilidade neurossensorial que, juntamente com a diminuição dos efeitos da gravidade, são responsáveis pela melhora do tônus muscular postural". ${ }^{20: 6}$ 
Mazarini $^{20}$ ainda diz que a natação estimula as funções cardiorrespiratórias e do sistema locomotor, que atuam como fatores importantes na coordenação postural dos indivíduos com deficiência visual. Ela ainda permite que a coluna vertebral se mantenha numa posição correta durante sua prática, sendo importante na educação postural. ${ }^{20}$

A natação mostra-se ainda como uma das modalidades mais adequadas para verificar o processo de inclusão da pessoa deficiente visual no esporte, pois possui características como: regras, formas de treinamento, competições, etc., favoráveis à inserção dessa clientela no esporte competitivo. ${ }^{19}$ Ao contrário de outras modalidades esportivas, praticadas pelas pessoas deficientes, essa possibilita a total independência e autonomia de seus praticantes. ${ }^{19}$

Além disso, Adams $^{6}$ diz que o calor da água favorece também o relaxamento dos músculos e anima o indivíduo a continuar explorando a movimentação dentro da água, o que pode ser interessante à pessoa deficiente visual e seu desenvolvimento motor durante sua prática.

\section{RESULTADOS}

A partir dos dados apresentados sobre a importância da prática da natação para as pessoas com deficiência visual e sua inclusão na sociedade, pudemos perceber que essa prática ainda é não está acessível a toda população, além de existirem poucos trabalhos que abordam esta problemática.

De acordo com Cordeiro, ${ }^{10}$ para que a natação se torne uma atividade acessível a toda a população brasileira, a educação física e o desporto para pessoas com deficiência precisam tratar da importância dos recursos humanos, das instalações, dos materiais e equipamentos, uma vez que a precariedade destes dificulta e, muitas vezes, impede o acesso a esta atividade.

Segundo Devide, ${ }^{21}$ a maior oferta dessa modalidade esportiva, característica dos dias atuais, está no fato do aumento no número de academias, clubes e escolas de natação que

Conexões: revista da Faculdade de Educação Física da UNICAMP, Campinas, v. 10, n. 2, p. 196-213, maio/ago. 2012.205 ISSN: 1983-9030 
oferecem sua prática, comprovando sua elitização pela sociedade.

O mesmo autor, em sua pesquisa com professores de educação física proprietários de academias, conclui que a natação se tornou uma modalidade elitista, sendo esta praticada, principalmente, em instituições privadas. ${ }^{21}$ Além disso, em muitos casos, não existem piscinas públicas para o desenvolvimento de um projeto comunitário, aspecto que é determinante para a acessibilidade de toda a população. ${ }^{21}$ Dessa forma, o praticante deve vincular-se às instituições privadas para que ocorra sua prática, dificultando ainda mais seu acesso.

Em um estudo realizado por Moreira, ${ }^{22}$ com uma população composta por 66 pessoas deficientes visuais, foram apresentados os principais motivos que levam esta população a não praticar nenhuma atividade física.

Dentre os principais motivos citados estão falta de transporte adequado (63\%), falta de desporto adaptado e locais próprios para sua prática (52\%), medo da exclusão (44\%), falta de material adequado (41\%), condição financeira (37\%), falta de profissional especializado (33\%), entre outros.

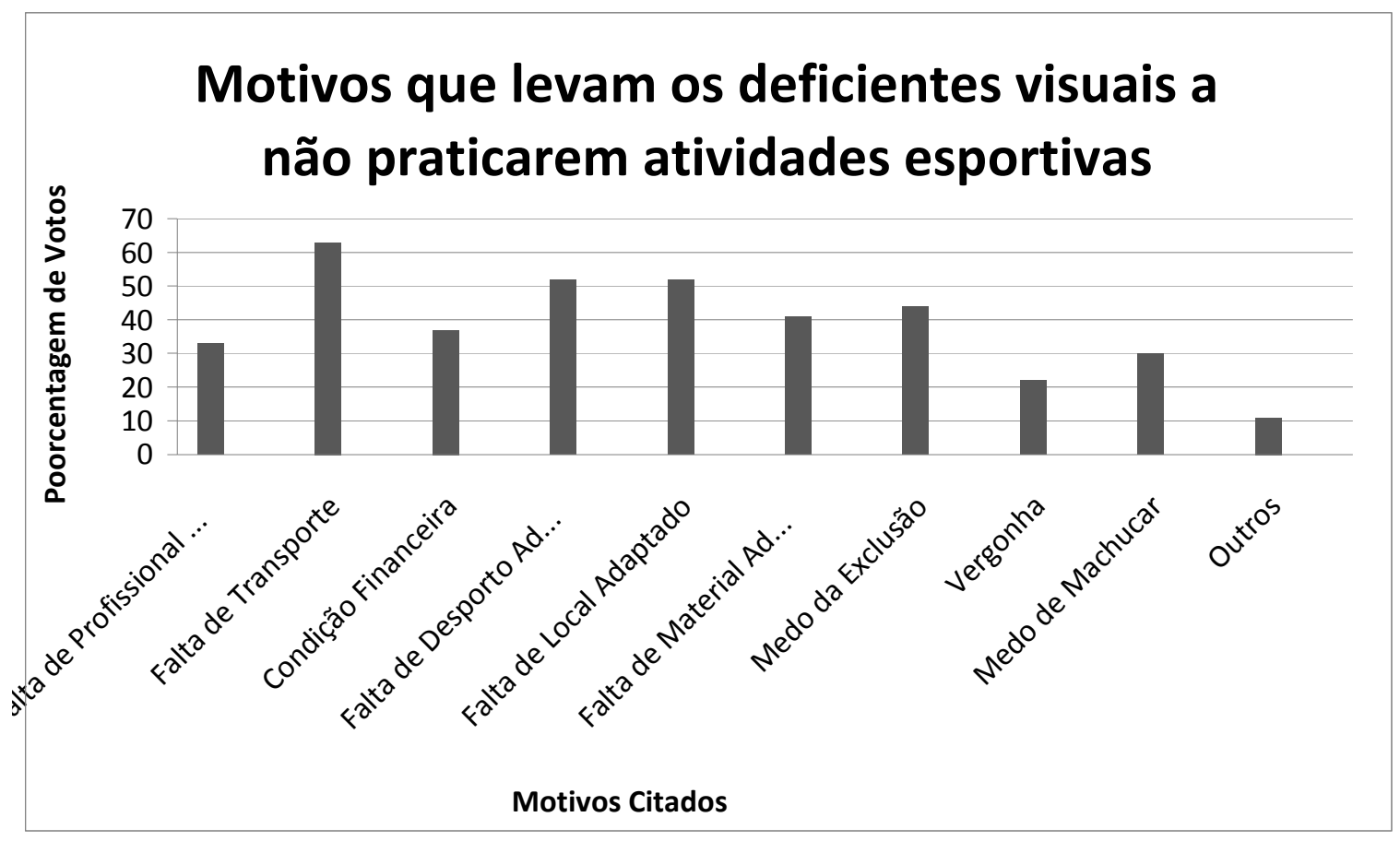

Gráfico 1 - Motivos que impedem a prática esportiva pelos deficientes visuais.

Conexões: revista da Faculdade de Educação Física da UNICAMP, Campinas, v. 10, n. 2, p. 196-213, maio/ago. 2012.206 ISSN: 1983-9030 
Vale ressaltar que, no estudo apresentado, cada pessoa poderia selecionar um ou mais motivos que impediam a prática de atividades físicas adaptadas.

\section{DISCUSSÃO}

De acordo com o gráfico apresentado, pode-se inferir que o principal motivo que leva à precariedade do acesso ao esporte adaptado no Brasil ainda está inserido num problema geral da sociedade brasileira, que é a falta de transporte público, que possibilite o acesso aos locais de prática esportiva.

Em seguida aparecem a falta de desporto adaptado e a falta de local adaptado como fatores limitantes para a prática esportiva, totalizando 52\% das pessoas deficientes visuais entrevistadas durante o estudo. A partir deste dado, pode-se inferir que muitas das atividades adaptadas oferecidas no país ainda estão dentro de locais restritos e que não chegam ao conhecimento da população deficiente visual, limitando o seu acesso. Além disso, grande parte dos locais destinados a prática esportiva ainda não foram adaptados adequadamente para que ofereçam total acessibilidade a estas pessoas.

Sendo assim, as condições precárias para a acessibilidade, nestes locais de prática da natação, podem se configurar como um dos principais fatores de impedimento para a participação mais efetiva e envolvida do aluno com deficiência nas atividades de ensino e, conseqüentemente, a aprendizagem da natação. ${ }^{10}$

Pensando na inclusão da pessoa deficiente visual na prática da natação, um conjunto de medidas coloca-se à tona, indo ao encontro das diversas necessidades destes alunos que, conseqüentemente, farão uso das instalações, serviços e materiais. ${ }^{10}$

Como se pode observar no gráfico apresentado, um dos principais motivos que impedem a prática esportiva pelas pessoas deficientes visuais é a falta de um local adaptado. Sendo assim, as primeiras recomendações devem se referir à eliminação de barreiras arquitetônicas, representadas por escadas e batentes, que podem dificultar o deslocamento das pessoas com deficiência visual que, muitas vezes são dependentes de bengalas para 
localização no espaço. ${ }^{10}$

No que diz respeito às instalações do ambiente da piscina, Yatsuda ${ }^{23}$ considera importante que a profundidade da piscina esteja dentro de um padrão ideal, sendo o de, aproximadamente, 1,30 metros, pois assim o professor sente mais estabilidade para sustentar os que precisarem de apoio. Para que isto seja possível nas instituições privadas, o uso de plataformas para a diminuição da profundidade pode ser uma opção a ser utilizada. Outro fator importante são as escadas dentro das piscinas, que devem ter seus degraus com pouco espaçamento entre eles, indo até o fundo e com corrimão para o apoio das pessoas deficientes. ${ }^{23}$ Também deve haver barras laterais nas piscinas para o apoio das pessoas que tenham dificuldade na locomoção e piso antiderrapante em toda a extensão da piscina. $^{23}$

De acordo com Cordeiro, ${ }^{10}$ outro fator importante nas instalações da piscina são as bordas e degraus de acesso, que devem ser de formato arredondado para prevenir acidentes com os alunos.

O caminho que as pessoas deficientes atravessam até chegar à piscina também deve estar dentro de alguns padrões para que sejam evitados alguns acidentes. O vestiário também deve ter piso antiderrapante, barras de segurança e sustentação dentro dos boxes. ${ }^{23}$ Além disso, todas as instalações devem ser suficientemente largas para a locomoção segura dessas pessoas. ${ }^{10}$

A falta de profissionais especializados para trabalharem com as pessoas deficientes é outro motivo citado como impedimento para a prática esportiva, como demonstrada no gráfico. Sendo assim, os professores devem estar preparados para desenvolverem as potencialidades de seus alunos, sendo estes deficientes ou não. Segundo Cordeiro, ${ }^{10}$ um dos principais papéis desempenhados pelo professor é o de inclusão das pessoas deficientes no ambiente social, promovendo a integração destes alunos com os outros não deficientes, em aulas em que todos aprendam juntos.

Assim, o professor deve estar seguro das estratégias que utilizará para atingir seus objetivos estabelecidos em planejamento prévio, além dos conteúdos que contemplarão 
cada uma das aulas. ${ }^{10}$ Cordeiro $^{10}$ ainda diz que, mais do que tudo, o professor deve proporcionar à pessoa deficiente segurança e afetividade, elementos fundamentais para o desenvolvimento desse grupo de pessoas.

Outro elemento que influencia na prática esportiva de pessoas deficiente visuais é a falta do material adequado para que esta seja realizada. Sobre isso, Yatsuda ${ }^{23}$ ressalta que os materiais didáticos devem ser organizados de forma a evitar acidentes. Dessa forma não devem ser pontiagudos ou cortantes e devem estar localizados longe das bordas das piscinas para a segurança dos alunos na entrada e saída destas. ${ }^{23}$

Diante da citação da condição financeira como fator limitante para a prática esportiva, e a constatação de que a natação se tornou um esporte elitista praticado principalmente em instituições privadas, acredita-se que, talvez, uma possível solução para a viabilização da natação para toda a comunidade, inclusive para a pessoa deficiente, possa partir da iniciativa privada. $^{21}$

Para finalizar, pode-se ressaltar que o fator psicológico da pessoa deficiente visual também deve ser levado em consideração quando o assunto é adesão a um determinado esporte, já que o medo de ser excluído, de se machucar, a vergonha de se expor e a sensação de estar no meio de muitas pessoas foram citadas no estudo de Moreira ${ }^{22}$ como fatores limitantes dessa prática.

Devido a este fato a inclusão da pessoa deficiente não deve ser focada somente na quebra das barreiras arquitetônicas existentes na sociedade, já que as barreiras sociais ainda são muitas e podem impedir que esta população pratique o esporte adaptado, inclusive a natação. De acordo com Cordeiro ${ }^{10}$, a quebra destas barreiras sociais deve partir, inicialmente, do professor, que tem a possibilidade de realizar aulas em conjunto com pessoas deficientes e não deficientes, fazendo com que todos os alunos interajam e se integrem entre si.

\section{CONSIDERAÇÕES FINAIS}

Com a realização deste estudo, pode-se considerar que a situação da acessibilidade para as

Conexões: revista da Faculdade de Educação Física da UNICAMP, Campinas, v. 10, n. 2, p. 196-213, maio/ago. 2012.209 ISSN: 1983-9030 
pessoas deficientes visuais à prática da natação ainda é muito precária no país, considerando alguns dos requisitos básicos para este fim, como a quebra de barreiras arquitetônicas nos espaços de prática e a quebra das barreiras sociais ainda existentes dentro da sociedade brasileira.

Muitas das instituições que oferecem a modalidade ainda não estão preparadas para receberem pessoas deficientes visuais, seja por falta de espaço adequado à sua execução, por falta de materiais e profissionais especializados, ou ainda por não estarem desvinculados dos diversos preconceitos inerentes à sociedade como um todo. De acordo com Cordeiro: ${ }^{10: 19}$

Para tanto, a educação física e o desporto para pessoas com deficiência precisam tratar da importância dos recursos humanos, das instalações, dos materiais e equipamentos [...] uma vez que a precariedade destes dificulta $\mathrm{e}$, muitas vezes, impede o acesso a essas atividades.

Sobre a importância da prática da natação pelas pessoas deficientes visuais considera-se que esta é uma modalidade que, se bem direcionada e explorada pelo profissional de educação física, pode trazer inúmeros benefícios à vida da pessoa deficiente visual, sendo estes físicos ou sociais.

Mas vale ressaltar que a prática dentro das instituições de ensino não deve ser realizada de forma separada e excludente. Reforça-se aqui a idéia de que a modalidade deve ser trabalhada em conjunto com os outros alunos, de forma a proporcionar integração entre estes, além de incluir a pessoa deficiente no ambiente esportivo, mostrando à sociedade que estes podem praticar a modalidade como e em conjunto com qualquer outra pessoa considerada normal. Cabe ao professor desenvolver aulas que levem em consideração as possibilidades de cada aluno e não as defasagens que uns têm em relação aos outros.

Neste ponto, considera-se de extrema importância a iniciativa das instituições privadas de ensino da natação para que a modalidade se torne acessível a qualquer população, inclusive às pessoas deficientes visuais, já que boa parte de sua prática esta restrita aos ambientes privados de ensino.

Para finalizar, deve-se ressaltar a importância da realização de mais estudos sobre a 
questão da acessibilidade de pessoas deficientes visuais à prática da natação, já que este é um tema relativamente novo e que ainda necessita de maiores embasamentos teóricos e práticos, sendo estes ainda muito precários, mas de extrema importância para o um desenvolvimento igualitário da sociedade do século XXI.

\section{REFERÊNCIAS}

${ }^{1}$ ORGANIZAÇÃO MUNDIAL DA SAÚDE (OMS). Países: datos estadísticos. Disponível em: <http://www.who.int/countries/bra/es/>. Acesso em: 24 mar. 2010.

\section{${ }^{2}$ INSTITUTO BRASILEIRO DE GEOGRAFIA E ESTATÍSTICA (IBGE) Censo 2000.} Disponível em:

<http://www.ibge.gov.br/home/estatistica/populacao/default_censo_2000.shtm>. Acesso em: 21 abr. 2010.

${ }^{3}$ BRASIL. Ministério da Saúde. Manual de legislação em saúde da pessoa portadora de deficiência. Brasília, 2006.

${ }^{4}$ ABREU, G. R. A importância da natação para o portador de deficiência visual. 1996. 31 f. (Monografia em Educação Física e Adaptação) - Faculdade de Educação Física, Universidade Estadual de Campinas, Campinas, 1996.

${ }^{5}$ MAZARINI, C. Natação para crianças portadoras de deficiência visual: uma proposta de ensino. 1992. 97 f. (Dissertação de Mestrado em Educação Especial) - Faculdade de Educação Física, Universidade Estadual de Campinas, Campinas, 1992.

${ }^{6}$ ADAMS, R. C. Jogos, esportes e exercícios para o deficiente físico. 1985.

${ }^{7}$ PIOVESAN, A.; TEMPORINI, E. R. Pesquisa exploratória: procedimento metodológico para o estudo de fatores humanos no campo da saúde pública. Revista de Saúde Pública, São Paulo, v. 29, n. 4, ago. 1995.

Conexões: revista da Faculdade de Educação Física da UNICAMP, Campinas, v. 10, n. 2, p. 196-213, maio/ago. 2012.211 ISSN: 1983-9030 
${ }^{8}$ ARANHA, M. S. F. Integração social do deficiente: análise conceitual e metodológica. Temas em Psicologia, Ribeirão Preto, n. 2, p. 63-70, 1995.

${ }^{9}$ CARMO, A. A. Deficiência física: a sociedade brasileira cria, "recupera" e discrimina. 1989. Tese (Doutorado em Educação) - Faculdade de Educação, Universidade Estadual de Campinas, Campinas, 1989.

${ }^{10}$ CORDEIRO, T. P. Ambiente e acessibilidade para pessoas com deficiência no desenvolvimento de atividades esportivas em piscinas: um estudo de casos. 2010. Dissertação (Mestrado em Ambiente e Desenvolvimento) - Centro Universitário Univates, Lajeado, 2010. Disponível em: <www.univates.br/bdu>. Acesso em: 23 ago. 2010.

${ }^{11}$ SASSAKI, R. K. Inclusão social: os novos paradigmas para todos os grupos minonitários. 1997. Disponível em: <http://www.entreamigos.com.br.temas>. Acesso em: 24 ago. 2010.

${ }^{12}$ SANTOS, A. Representações de pessoas cegas sobre a organização espaço-temporal tomando como referência seu próprio corpo. 1996. Dissertação (Mestrado em Educação Física) - Faculdade de Educação Física, Universidade Estadual de Campinas, Campinas, 1996.

${ }^{13}$ COSTA, A. M.; SOUSA, S. B. Educação física e esporte adaptado: história, avanços e retrocessos em relação aos princípios da integração/inclusão e perspectivas para o século XXI. Revista Brasileira de Ciência do Esporte, Campinas, v. 25, n. 3, p. 27-42, 2004.

${ }^{14}$ ARAÚJO, P. F. Desporto adaptado no Brasil: origem, institucionalização e atualidade. Brasília: Ministério da Educação e do Desporto/INDESP, 1998.

${ }^{15}$ AZEVEDO, P. H.; BARROS, J. F. O nível de participação do Estado na gestão do esporte brasileiro como fator de inclusão social de pessoas portadoras de deficiência. Revista Brasileira de Ciência e Movimento, v. 12, n. 1, p. 77-84, 2004.

${ }^{16}$ ARAUJO JÚNIOR, B. Natação: saber fazer ou fazer sabendo? Campinas: Ed. da Conexões: revista da Faculdade de Educação Física da UNICAMP, Campinas, v. 10, n. 2, p. 196-213, maio/ago. 2012. ${ }^{212}$ ISSN: 1983-9030 
Unicamp, 1993.

${ }^{17}$ DAMASCENO, L. G. Natação, psicomotricidade e desenvolvimento. Brasília: 1992.

${ }^{18}$ PAULA, V. R. Desporto para cegos no Brasil: goalball, uma prática saudável. 2001. 50 f. (Monografia em Educação Física) - Faculdade de Educação Física, Universidade Estadual de Campinas, Campinas, 2001.

${ }^{19}$ LUZ, L. M. R. A natação, o cego e o deficiente visual: a inclusão e suas implicações no desporto de rendimento. 2003. 99 f. Dissertação (Mestrado em Educação Física) Faculdade de Educação Física, Universidade Estadual de Campinas, Campinas, 2003.

\section{${ }^{20}$ MAZARINI, C. A criança portadora de deficiência visual e a alegria de aprender a} nadar. São Paulo: Ed. Santos, 2006.

${ }^{21}$ DEVIDE, F. P. O discurso de proprietários de academias sobre a prática da natação como atividade de lazer: inclusão ou elitização social? Movimento, ano 6, n. 12, 2001.

${ }^{22}$ MOREIRA, W. C. et al. Fatores que influenciam a adesão de deficientes motores e deficientes visuais à prática desportiva. Revista Digital, Buenos Aires, ano, 11, n. 104, jan. 2007. Disponível em: <http://www.efdeportes.com>. Acesso em: 16 out. 2010.

${ }^{23}$ YATSUDA, A. G. Natação escolar adaptada: propondo a inclusão de corpos (d)eficientes na Educação Física. Revista Digital, Buenos Aires, ano 14, n. 142, mar. 2010. Disponível em: <http://www.efdeportes.com>. Acesso em: 16 out. 2010.

Recebido em: 19 março 2012.

Aceito em: 06 julho 2012. 